\title{
Péptidos antioxidantes derivados de la digestión gastrointestinal de proteínas de amaranto: Una primera aproximación a la evaluación de su absorción intestinal y posterior actividad
}

\author{
Antioxidant peptides from gastrointestinal digestion \\ of amaranth proteins: A first approach to the evaluation \\ of the intestinal absorption and subsequent activity
}

Orsini Delgado (1), María C., Añón, María C. (1), Tironi, Valeria A. (1)

(1) Centro de Investigación y Desarrollo en Criotecnología de Alimentos (CIDCA) (CCT La Plata - CONICET, UNLP). Contacto: vtironi@quimica.unlp.edu.ar

RECIBIDO: 29/2/2016 - APROBADO: 15/6/2016

\begin{abstract}
Resumen
Se evaluó la absorción intestinal de péptidos antioxidantes generados por digestión gastrointestinal simulada de proteínas de Amaranthus mantegazzianus. Digeridos gastrointestinales de aislado proteico (AD) y de hidrolizado con alcalasa (HD) fueron separados mediante FPLC de exclusión molecular en fracciones cuya actividad fue evaluada por los métodos ORAC y HORAC. Las fracciones más activas (0,7-1,8 kDa) fueron sometidas a ensayos de simulación de la absorción intestinal utilizando monocapas de células Caco-2/TC7 sobre insertos de poliéster $(0,4 \mu \mathrm{m})$, colocando las muestras en la cámara apical (incubación $3 \mathrm{~h}, 37^{\circ} \mathrm{C}$ ). Se analizó la concentración peptídica (método de Lowry), composición molecular (RP-HPLC) y actividad antioxidante (método ORAC) de las muestras iniciales, cámaras apical y basolateral. Ciertos péptidos fueron capaces de atravesar la monocapa celular, previa modificación en algunos casos. El potencial antioxidante de todas las cámaras apicales aumentó debido probablemente a la acción de las peptidasas del borde en cepillo. Las cámaras basolaterales presentaron aumento o disminución del potencial antioxidante respecto a las cámaras apicales, dependiendo del tipo de moléculas que atravesó en cada caso la monocapa celular. Los resultados sugieren una absorción intestinal potencial de componentes peptídicos antioxidantes de amaranto posibilitando su acción en tejidos blanco internos del organismo.

Palabras clave: Amaranto, péptidos antioxidantes, digestión gastrointestinal, absorción intestinal.
\end{abstract}

\begin{abstract}
Intestinal absorption of antioxidant peptides from simulated gastrointestinal digestion of Amaranthus mantegazzianus proteins was evaluated. Gastrointestinal digests (AD and HD) were obtained from protein isolate $(\mathrm{A})$ and its alcalase hydrolysate $(\mathrm{H})$ and separated by molecular exclusion FPLC into fractions which activity was evaluated by the ORAC and HORAC methods. Active fractions (0,7-1,8 kDa) were submitted to intestinal absorption simulation using monolayers of Caco- $2 / \mathrm{TC} 7$ cells on polyester inserts $(0,4 \mu \mathrm{m})$. Samples were seeded in the apical compartment (incubation $3 \mathrm{~h}, 37^{\circ} \mathrm{C}$ ). Original, apical and basolateral samples were analysed for peptide concentration (Lowry method), molecular composition (RP-HPLC) and antioxidant activity (ORAC method). Some peptides were able to cross the cell monolayer, with previous modifications in some cases. The antioxidant potential of the apical compartments increased in all cases due probably to the action of the brush border peptidases. Basolateral compartments presented increments or reductions of the antioxidant potentials respect to the apical ones, depending on which molecules crossed the monolayer in each case. Results suggest a potential intestinal absorption of amaranth antioxidant peptides which would be able to act inside the organism.
\end{abstract}

Keywords: Amaranth, antioxidant peptides, gastrointestinal digestion, intestinal absorption. 


\section{Introducción}

Trabajos previos realizados en nuestro laboratorio indican que la digestión gastrointestinal simulada de las proteínas de amaranto genera péptidos con una interesante actividad antioxidante (Orsini Delgado, et al., 2011; Orsini Delgado, et al., 2015). Sin embargo, para poder ejercer su actividad in vivo en sistemas u órganos internos del organismo estos compuestos deben ser absorbidos a través del epitelio intestinal.

Los componentes de origen proteico que entran en contacto con el lumen intestinal son escindidos por diversas peptidasas celulares, generando desde aminoácidos libres hasta tripéptidos, los cuales pueden ser absorbidos de manera intacta hacia el citosol (Vermeirssen, et al., 2004). Sin embargo, ocurre con baja frecuencia que péptidos o hasta proteínas intactas puedan atravesar el lumen intestinal y llegar a la circulación sanguínea sin sufrir ninguna modificación. La absorción de péptidos puede ocurrir a través de diversos mecanismos tales como: 1) Transporte activo secundario con sodio; 2 ) transporte paracelular en el que péptidos hidrofílicos pueden ser absorbidos por medio de la unión de dos células contiguas; 3 ) transportador Pep-T1 localizado en la membrana apical (di y tripéptidos), y 4) difusión transcelular de péptidos hidrofóbicos. En el interior de los enterocitos, los péptidos pueden ser hidrolizados por peptidasas intracelulares. La membrana basolateral intestinal también posee un transportador que facilita la salida de pequeños péptidos resistentes a la hidrólisis (Vermeirssen, et al., 2004). Si bien existe una relación entre las características fisicoquímicas y el posible mecanismo de absorción, no se puede predecir el comportamiento de un péptido en particular. A fin de poder evitar la utilización de ensayos in vivo para el estudio de la absorción, los cuales demandan un elevado número de animales, grandes cantidades de la muestra en estudio, mucho tiempo y análisis complejos, además de ser muy costosos, se recurre a la evaluación in vitro de la permeabilidad intestinal mediante la utilización de tejido intestinal o de cultivos celulares. Frente a los ensayos con tejidos animales o ensayos in vivo, la utilización de cultivos celulares tiene como principal desventaja que estos provienen de sistemas cancerígenos en la mayoría de los casos y, por lo tanto, retienen ciertas características de estos sistemas (e.g. estas células pueden ser cultivadas in vitro y es posible realizar varios pasajes). No obstante, estos cultivos celulares imitan muchas de las propiedades metabólicas y de transporte de los sistemas intestinales. Si bien pueden presentar variaciones en la expresión de transportadores o actividades enzimáticas entre los distintos pasajes, este modelo de estudio cuenta con varias ventajas que justifican su utilización, entre ellas: fácil manipulación, posibilidad de crecimiento sobre soportes porosos, requerimiento de poca cantidad de muestra, facilidad en el control de aquellas condiciones que pueden afectar el transporte $(\mathrm{pH}$, concentración de iones, temperatura, presencia de inhibidores metabólicos, etcétera). Dentro de las líneas más utilizadas se encuentran la Caco-2 proveniente de carcinoma de colon humano, debido a su capacidad de diferenciación, formación de microvellosidades, uniones ocluyentes, enzimas hidrolíticas y sistemas de transporte mediados por transportadores para azúcares, aminoácidos y otras drogas (Antunes, et al., 2013). En las últimas décadas, diversos estudios han demostrado la capacidad de ciertos péptidos de atravesar la barrera intestinal. Como ejemplos, pueden mencionarse el fragmento 193-209 de $\beta$-caseína (17 aminoácidos, $1881 \mathrm{Da}$, hidrofóbico, con alto contenido de prolina) absorbido mediante la ruta transcelular (Regazzo, et al., 2010), o un pentapéptido derivado de $\beta$-caseína que demostró ser absorbido mediante la ruta paracelular (Quiros, et al., 2008).

El objetivo de este trabajo fue evaluar la capacidad potencial de péptidos antioxidantes obtenidos por digestión gastrointestinal simulada de proteínas de amaranto de atravesar una pared intestinal simulada.

\section{Materiales y Métodos}

\section{Obtención de aislado e hidrolizado proteico de Amaranthus mantegazzianus}

I.a. Aislado (A). Se utilizaron semillas de cultivos realizados en la Facultad de Agronomía de la Universidad Nacional de La Pampa, Argentina. Se preparó harina moliendo las semillas (aproximadamente $1 \mathrm{~kg}$ ) en un molino Udy (malla de $1 \mathrm{~mm}$ ) y tamizando (cedazo de $0,092 \mathrm{~mm}$ de malla). La harina fue desgrasada con $\mathrm{n}$-hexano (10 g de harina/100 ml de n-hexano, agitación $5 \mathrm{~h}$ a temperatura ambiente de aproximadamente $20^{\circ} \mathrm{C}$, reposo $24 \mathrm{~h}$ y filtración). A fue preparado por extracción de las proteínas a partir de una suspensión de harina en agua bidestilada $(10 \mathrm{~g} / 100 \mathrm{ml})$ a $\mathrm{pH}=9$, precipitación isoeléctrica a $\mathrm{pH}=5$, neutralización y liofilización (Martinez y Añón, 1996).

I.b. Hidrolizado proteico con alcalasa $(\mathrm{H})$. Se preparó una suspensión ( $1 \mathrm{~g} \mathrm{~A} / 100 \mathrm{ml}$ de $\mathrm{NaOH} 1 \mathrm{mM}, \mathrm{pH}=10)$ y se incubó en agitación $\left(1 \mathrm{~h}, 37^{\circ} \mathrm{C}\right)$ manteniendo el pH constante. Se adicionó alcalasa ( $\geq 2,4 \mathrm{U} / \mathrm{g}$, Anson Units (Sigma), $8 \mu \mathrm{l} / 100 \mathrm{mg}$ de muestra) incubando durante $4 \mathrm{~h}$ a $37^{\circ} \mathrm{C}$. Se detuvo la reacción enzimática $\left(85^{\circ} \mathrm{C}, 10 \mathrm{~min}\right)$ y se liofilizó la suspensión (Tironi y Añón, 2010).

\section{Simulación de la digestión gastrointestinal}

A y $\mathrm{H}$ fueron sometidos a una fase de digestión estomacal: solución de pepsina (Pepsina 1:15000 MP Biomedicals, Inc.) (Pe) en $\mathrm{HCl} \mathrm{0,1} \mathrm{N} \mathrm{y} \mathrm{NaCl} \mathrm{0,03} \mathrm{M} \mathrm{(pH} \mathrm{=} \mathrm{2),} \mathrm{relación} \mathrm{Pe/pro-}$ teína $=1 / 10 \mathrm{p} / \mathrm{p}, 60 \mathrm{~min}, 37^{\circ} \mathrm{C}$; luego de neutralizar a $\mathrm{pH}=$ 6 con $\mathrm{NaOH}$, se continuó con una fase intestinal: solución de pancreatina (Pancreatina Porcina 4X-USP MP Biomedicals, Inc.) $(\mathrm{Pa})$ en $\mathrm{NaHCO} 30,1 \mathrm{~N}(\mathrm{pH}=6)$, relación Pe/proteína $=1 / 10 \mathrm{p} / \mathrm{p}, 60 \mathrm{~min}, 37^{\circ} \mathrm{C}$. Se detuvo la actividad enzimática $\left(85^{\circ} \mathrm{C}, 10 \mathrm{~min}\right)$ y las suspensiones fueron liofilizadas (Orsini Delgado, et al., 2011), obteniéndose los digeridos AD y HD.

\section{Separación de fracciones por cromatografía FPLC de filtración en gel}

Fracciones solubles en tampón fosfato $35 \mathrm{mM}(\mathrm{pH}=7,8)$ de AD y HD fueron separadas mediante FPLC utilizando una columna de exclusión molecular Superdex 30 prep grade (GE Healthcare, rango de separación óptimo $<10 \mathrm{kDa}$ ), en un equipo $\mathrm{AKTA} \mathrm{Pu}-$ rifier (GE Healthcare Bioscience $\mathrm{AB}$ ) a temperatura ambiente, empleando como fase móvil el tampón de solubilización de las muestras. La columna utilizada presentaba un volumen total $\left(\mathrm{V}_{\mathrm{t}}\right)$ de $118 \mathrm{ml}$, el volumen de inyección fue de $2 \mathrm{ml}$ y el flujo de $0,8 \mathrm{ml} / \mathrm{min}$. La calibración previa de la columna se realizó utilizando azul dextrano para el volumen de exclusión $\left(\mathrm{V}_{0}=\right.$ $40,75 \mathrm{ml})$, ribonucleasa $\mathrm{A}(13,7 \mathrm{kDa})$, aprotinina $(6,5 \mathrm{kDa})$, 
vitamina $\mathrm{B}_{12}(1,35 \mathrm{kDa})$ y tirosina $(181,2 \mathrm{Da})$. Los polipéptidos $y$ péptidos fueron detectados midiendo la absorbancia a 210 $\mathrm{nm}$. Se colectaron fracciones cada 2 min a partir del $\mathrm{V}_{0}$ y se obtuvo un total de 51 fracciones de $1,6 \mathrm{ml}$ cada una.

\section{Determinación de la actividad antioxidante de las fracciones}

Dada la alta cantidad de fracciones colectadas de cada una de las muestras, en una primera instancia se realizó un screening de la actividad antioxidante sobre muestras constituidas por tres fracciones FPLC consecutivas. En una segunda instancia se analizó la actividad de aquellas fracciones individuales originales que constituían las muestras con mayor actividad en el primer screening. Se utilizaron dos metodologías:

IV.a. Ensayo ORAC. Se realizó el protocolo previamente optimizado en nuestro laboratorio (Orsini Delgado, et al., 2015). Brevemente, se mezclaron $150 \mu \mathrm{l}$ de la solución de fluoresceína 53,3 nM con $25 \mu \mathrm{l}$ de muestra, tampón fosfato (control negativo) o Trolox (concentraciones entre 6,25 y $75 \mu \mathrm{M}$ ) y $25 \mu \mathrm{l}$ de AAPH $160 \mathrm{mM}$ en placas negras de 96 pocillos. Las placas se incubaron a $37^{\circ} \mathrm{C}$ con agitación continua y se realizaron lecturas de fluorescencia $\left(\lambda_{\text {exc }}: 485 \mathrm{~nm}\right.$, $\lambda_{\text {em }}: 535 \mathrm{~nm}$ ) cada 1 min durante $45 \mathrm{~min}$ en un lector de microplacas (SYNERGY HT - SIAFRT, Biotek Instruments, Vermont, Estados Unidos). Se calculó el área bajo la curva (AUC) y el porcentaje de secuestro de los radicales peroxilo (ROO•) obteniéndose el valor Trolox equivalente $(\mu \mathrm{M})$ a partir de la curva de calibración de Trolox.

IV. b. Ensayo HORAC. Se midió la capacidad de prevenir la formación de radicales hidroxilo sobre las mismas fracciones seleccionadas para el ensayo ORAC. Se utilizó el protocolo previamente optimizado (Orsini Degado, et al., 2015): se mezclaron $20 \mu \mathrm{l}$ de las muestras o del tampón (control negativo) con $190 \mu \mathrm{l}$ de la solución de fluoresceína $0,0603 \mu \mathrm{M}, 15 \mu \mathrm{l}$ de $\mathrm{H}_{2} \mathrm{O}_{2}, 0,75 \mathrm{M}$ y $75 \mu \mathrm{l}$ de la solución de $\mathrm{Co}^{+2}\left(10 \mathrm{mg}\right.$ de ácido picolínico con $11 \mathrm{mg} \mathrm{de} \mathrm{CoCl}_{2} \cdot 6 \mathrm{H}_{2} \mathrm{O}$ en $50 \mathrm{ml}$ de agua bidestilada) en placas negras de 96 pocillos, se incubó con agitación durante $3 \mathrm{~h}$ en un lector de microplacas (SYNERGY HT-SIAFRT, Biotek) realizando medidas de fluorescencia $\left(\lambda_{\text {exc }}: 485 \mathrm{~nm}, \lambda_{\text {em }}: 535 \mathrm{~nm}\right)$ cada $1 \mathrm{~min}$. Se calculó el área bajo la curva (AUC) y el porcentaje de inhibición de la formación de radicales hidroxilo. Como compuesto de referencia se utilizó el ácido clorogénico en concentraciones entre 0,05 y $0,5 \mathrm{mg} / \mathrm{ml}$. Se calculó el valor de ácido clorogénico equivalente $(\mathrm{mg} / \mathrm{ml})$ para cada una de las muestras.

\section{Simulación de la absorción intestinal}

Para la realización de estos ensayos se utilizaron cultivos de células Caco-2/TC7, clon de la línea Caco-2 proveniente de un carcinoma de colon humano, las cuales expresan varias enzimas intestinales y transportadores, incluyendo el transportador de péptidos Pep-T1, y permiten el transporte paracelular (Hidalgo, et al., 1989).

\section{V.1. Ensayos de citotoxicidad}

V.1.a. Ensayo del Rojo Neutro. Se sembraron $2,5 \times 10^{4}$ células/pocillo en placas de 96 pocillos y se incubaron hasta confluencia. Se lavó dos veces con PBS y se adicionaron las muestras a estudiar, las cuales se encontraban solubilizadas en medio DMEM de adhesión. Se incubó durante $3 \mathrm{~h}$ a $37^{\circ} \mathrm{C}$ con un $5 \%$ de $\mathrm{CO}_{2}$. Se lavó con PBS, se agregó medio conteniendo $100 \mu \mathrm{g} / \mathrm{ml}$ de rojo neutro y se incubaron las células durante $2 \mathrm{~h}$. Se descartó el medio con rojo neutro y se lavó 2 veces con $\mathrm{PBS}$ a $37^{\circ} \mathrm{C}$, para remover todo el colorante que no había sido incorporado por las células. Se fijaron las células con una solución al 5\% de formaldehído, se incubó 5 min a temperatura ambiente, se lavó dos veces con PBS y se solubilizó el colorante con DMSO, dejando reposar $20 \mathrm{~min}$ a temperatura ambiente. Se midió la absorbancia a $540 \mathrm{~nm}$ del sobrenadante en un lector de microplacas (SYNERGY HT-SIAFRT, Biotek). Se graficó\% de viabilidad celular en función de la concentración de muestra, asumiendo un $100 \%$ de viabilidad para aquellas células en las que no se había adicionado muestra (control de viabilidad +) (Di Virgilio, et al., 2010).

V.1.b.Ensayo del MTT (bromuro de 3-(4,5-dimetiltiazol-2-il)-2,5-difeniltetrazolio). Se sembraron $2,5 \times 10^{4}$ células/pocillo en placas de 96 pocillos, incubándolas a $37^{\circ} \mathrm{C}$ $\left(5 \%\right.$ de $\left.\mathrm{CO}_{2}\right)$ hasta llegar a confluencia. Se adicionaron las muestras y se incubó $3 \mathrm{~h}\left(37^{\circ} \mathrm{C}, 5 \%\right.$ de $\left.\mathrm{CO}_{2}\right)$. Se lavó con PBS y se adicionó medio DMEN (sin color) conteniendo $0,5 \mathrm{mg} /$ $\mathrm{ml}$ de MTT, incubando $3 \mathrm{~h}$. Se lavó dos veces con PBS y se extrajo el colorante captado por las mitocondrias adicionando $100 \mu \mathrm{l} /$ pocillo de DMSO e incubando $10 \mathrm{~min}$ en agitación. Se midió la absorbancia a $570 \mathrm{~nm}$ del sobrenadante en un lector de microplacas (SYNERGY HT-SIAFRT, Biotek). La viabilidad celular se graficó como un\% del control, asumiendo un $100 \%$ de viabilidad para aquellas células a las que no se les adicionó ninguna muestra (Di Virgilio, et al., 2010).

\section{V.2. Ensayo de absorción sobre monocapas de células Caco2-TC7}

$200 \mu$ de suspensión de células Caco-2/TC7 (pasajes N 39-40 del cultivo ATCC) provenientes de cultivos confluentes realizados en cajas de $75 \mathrm{~cm}^{2}$ se sembraron sobre insertos de poliéster (Transwell (Corning), 0,4 $\mu \mathrm{m}, 12 \mathrm{~mm}$ de diámetro) en una concentración de $1 \times 10^{5}$ células $/ \mathrm{cm}^{2}$, colocando $600 \mu \mathrm{l}$ de DMEM en el pocillo (cámara basolateral). Se incubó a $37^{\circ} \mathrm{C}\left(5 \% \mathrm{CO}_{2}\right)$, realizando cada dos días cambio del medio de cultivo de ambas cámaras (apical y basolateral). Luego de cada cambio de medio se midió la resistencia eléctrica transepitelial (TEER, $\Omega . \mathrm{cm}^{2}$ ) a fin de evaluar la confluencia e integridad de las monocapas, uilizando un voltímetro Millicell ${ }^{\circledR}$-ERS (Millipore, USA). Una vez formada la monocapa (TEER constante), se adicionaron $500 \mu \mathrm{l}$ de PBS en las cámaras apical y basolateral del inserto y se incubó durante $20 \mathrm{~min}$ a $37^{\circ} \mathrm{C}\left(5 \% \mathrm{de} \mathrm{CO}_{2}\right)$. A continuación, el PBS de ambas cámaras fue removido y en la cámara apical se sembraron $200 \mu \mathrm{l}$ de las soluciones de péptidos en estudio, mientras que en la cámara basolateral se colocaron $600 \mu \mathrm{l}$ de PBS, manteniéndose en incubación durante $3 \mathrm{~h}$.

\section{V.3. Análisis por RP-HPLC}

Se analizaron las muestras tomadas de las cámaras apical y basolateral luego de la incubación y cada una de las muestras originales colocadas en la cámara apical. Se utilizó una columna analítica Sephasil Peptide C8, $12 \mu \mathrm{m}$, ST 4,6/250 (Pharmacia Biotech), con un equipo HPLC Waters (Waters Corp., Milford, MA) equipado con un detector de arreglo de diodo (DAD). Las muestras fueron eluidas con un gradiente lineal ( 0 a $100 \%$ en $55 \mathrm{~min}$ de solvente B (agua/acetonitrilo (35/65), ácido trifluoroacético (TFA) $650 \mu \mathrm{l} / \mathrm{l}$ ) en solvente A 
(agua/ acetonitrilo $(98 / 2)$, TFA $650 \mu \mathrm{l} / \mathrm{l}$ ), flujo $=1,1 \mathrm{ml} / \mathrm{min}$. Se colectaron fracciones cada $1 \mathrm{~min}$ entre los 2 y $60 \mathrm{~min}$.

\section{V.4. Determinación \\ de la concentración peptídica}

Se determinó la concentración peptídica de las distintas muestras (original, apical y basolateral) mediante el método de Lowry modificado (Stoscheck, 1990) en los casos de concentraciones menores a 0,1mg/ml (Tironi y Añón, 2010).

\section{V.5. Determinación \\ de la actividad antioxidante}

Se determinó la actividad antioxidante de las distintas muestras (original, apical y basolateral) mediante el método de ORAC previamente descripto.

\section{Resultados y Discusión}

\section{Separación de fracciones por FPLC}

Se llevó a cabo la separación de fracciones de las dos muestras obtenidas por digestión gastrointestinal simulada (AD y HD) de acuerdo a su tamaño molecular utilizando una columna de exclusión molecular preparativa Superdex 30 (rango de separación óptimo: $<10 \mathrm{kDa}$ ), la cual presentó la siguiente expresión para el cálculo de la masa molecular: $\log M M=1,549-2,546$ $\times \mathrm{K}_{\mathrm{av}}\left(\mathrm{r}^{2}=0,978\right)$, siendo $\mathrm{K}_{\mathrm{av}}=\left(\mathrm{V}_{\mathrm{e}}-\mathrm{V}_{0}\right) /\left(\mathrm{V}_{\mathrm{t}}-\mathrm{V}_{0}\right), \mathrm{V}_{\mathrm{e}}=$ volumen de elución. En las Figuras 1 y 2 se muestran los cromatogramas obtenidos para $\mathrm{AD}$ y $\mathrm{HD}$, respectivamente. Si bien se colectaron fracciones de 1,6 ml, inicialmente se mezclaron de a tres fracciones consecutivas y se obtuvieron 17 muestras a las que se les realizó una primera evaluación de la actividad antioxidante. Dichas muestras se señalan en los cromatogramas.

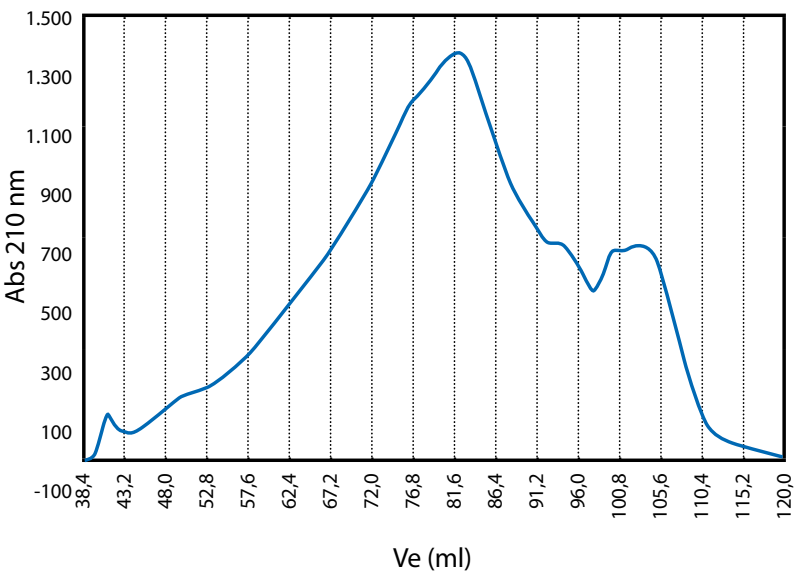

Figura 1. Cromatograma FPLC de exclusión molecular de $\mathrm{AD}$ señalando las muestras utilizadas para el primer screening de actividad antioxidante.

Al comparar los perfiles cromatográficos de ambos digeridos se pueden observar algunas similitudes. Los picos más importantes en ambas muestras aparecen en un rango de volúmenes de elución similares (muestras 6 a 14), y se encuentran constituidos, de acuerdo a la curva de calibración obtenida, por moléculas de entre 6,1 y $0,2 \mathrm{kDa}$, o sea, por

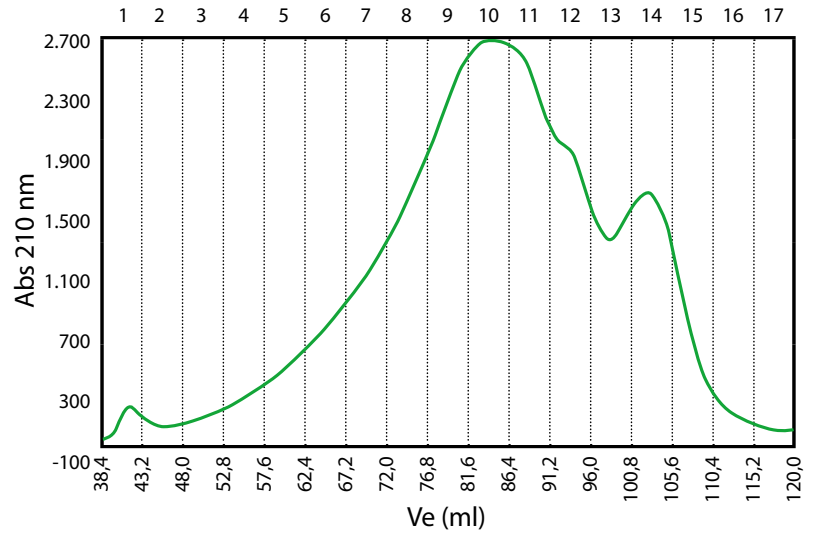

Figura 2. Cromatograma FPLC de exclusión molecular de HD señalando las muestras utilizadas para el primer screening de actividad antioxidante.

péptidos de entre 2 y 55 aminoácidos (considerando $110 \mathrm{Da}$ como masa molecular promedio de un aminoácido). Asimismo, las máximas absorbancias a $210 \mathrm{~nm}$ corresponden a las fracciones 9 (en el caso de AD) o 9 y 10 (para HD), las cuales contienen péptidos con masas moleculares de entre 1 y $2 \mathrm{kDa}$, o sea, péptidos de entre 9 y 19 aminoácidos.

\section{Actividad antioxidante de las fracciones}

Los valores Trolox eq. ( $\mu \mathrm{M})$ (ensayo ORAC) y Ácido clorogénico eq. $(\mathrm{mg} / \mathrm{ml})$ (ensayo HORAC) para las muestras provenientes de AD y HD se presentan en las Figuras 3 y 4 , respectivamente.

Como puede observarse en las figuras, las muestras más activas estuvieron comprendidas entre la 6 y la 14 correspondientes a masas moleculares de entre 6,1 y $0,2 \mathrm{kDa}$, las cuales también abarcaron la mayor área relativa de pico, un $81 \%$ del área total en el caso del AD y un $87 \%$ para HD. Las muestras que presentaron menor actividad en todos los casos (16 y 17) corresponden a la última zona de los cromatogramas (masas moleculares menores a las de un aminoácido) donde resulta muy baja la presencia de componentes detectables a $210 \mathrm{~nm}$, con áreas relativas de entre 0,4 y $1,3 \%$ solamente. A su vez, las muestras 1 a 5, correspondientes a moléculas de masas moleculares mayores a 6,1 kDa y la muestra 15 (masas moleculares menores a $0,2 \mathrm{kDa}$ ) presentaron actividades intermedias.

Teniendo en cuenta los resultados anteriores, se seleccionaron aquellas muestras que demostraron poseer mayor capacidad antioxidante por ambas metodologías (muestras 6 a 14), para evaluar a través de los mismos ensayos y protocolos la actividad de sus fracciones constituyentes. En el caso de las fracciones separadas a partir de AD (Figura 5) se puede observar que si bien todas las fracciones presentaron algún nivel de actividad por el ensayo ORAC, algunas de ellas exhibieron valores mayores de Trolox eq., tales como las fracciones 64 - 66 (Trolox eq. entre 242 y $293 \mu \mathrm{M}$ ) y las fracciones 50-52 (Tolox eq. entre 225 y $248 \mu \mathrm{M}$ ). En el caso del ensayo HORAC se observan más diferencias entre las actividades de las distintas fracciones; las fracciones 50-52 son las más activas, con valores de ácido clorogénico eq. de entre 403 y $467 \mu \mathrm{g} / \mathrm{ml}$, seguidas de las fracciones 45 a 49 y la 53 , con valores de entre 250 y $303 \mu \mathrm{g} / \mathrm{ml}$.

En el análisis de los resultados del ensayo ORAC de las fracciones provenientes de HD se observa una fracción de 
a.

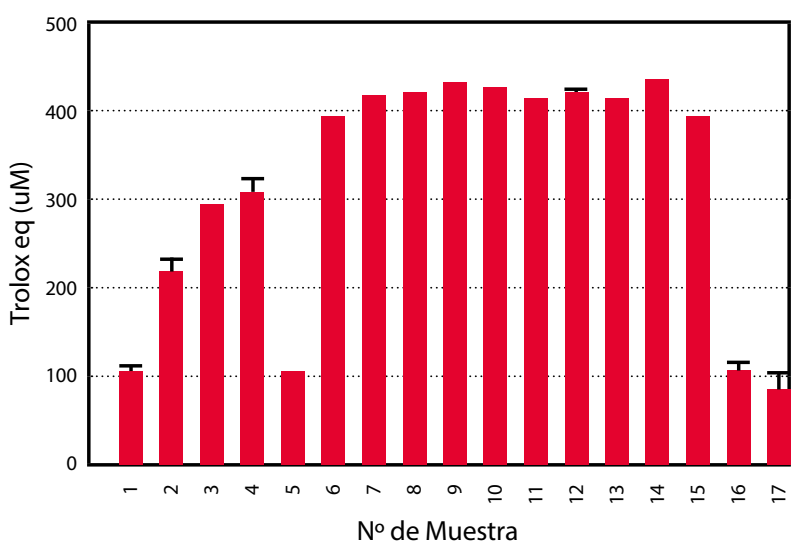

b.

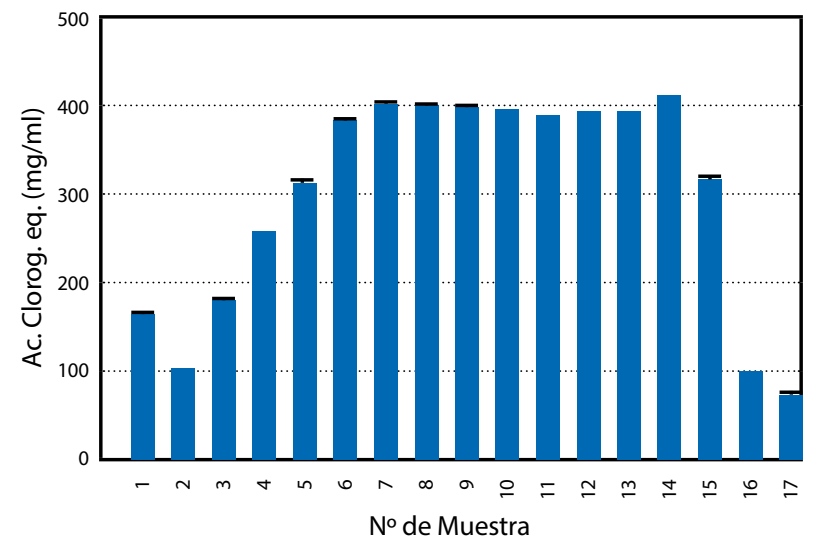

Figura 3. a. Valor Trolox eq $(\mu \mathrm{M})(\mathrm{ORAC})$ de las muestras provenientes de AD. b. Valor Ácido clorogénico eq. (mg/ $\mathrm{ml}$ (HORAC) de las muestras provenientes de AD. Los resultados se expresan como el promedio $\pm \operatorname{SD}(n=3)$.

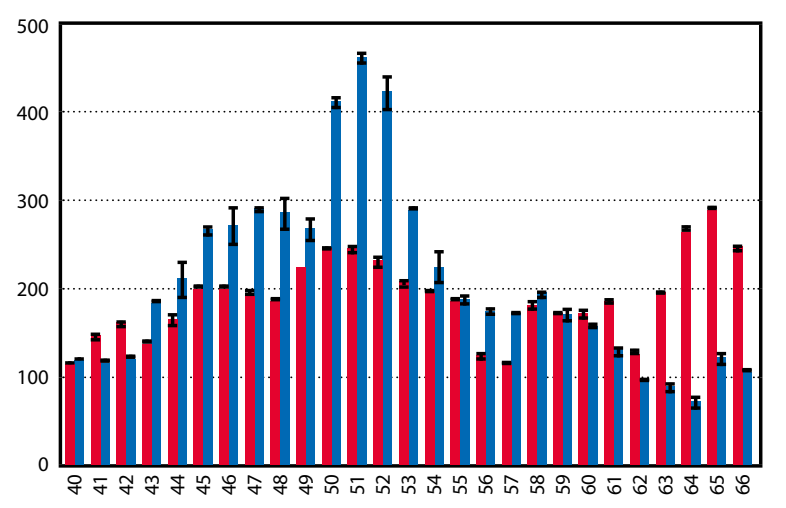

No de Fracción

Trolox eq (uM) Ac. Clorog. eq (ug/ml)

Figura 5. Valores Trolox eq $(\mu \mathrm{M})(\mathrm{ORAC})$ y Ácido clorogénico eq. $(\mu \mathrm{g} / \mathrm{ml})($ HORAC) de las fracciones constituyentes de las muestras 6-14 de AD. Los resultados se expresan como promedio $\pm S D(n=3)$.

mayor actividad (64) con un valor de Trolox eq. de $202 \mu \mathrm{M}$, seguida por varias fracciones con actividades comparables (51-53, 54, 55, 57, 59, 60 y 63) con valores de Trolox eq. de entre 100 y $139 \mu \mathrm{M}$, y el resto presenta menores valores. En

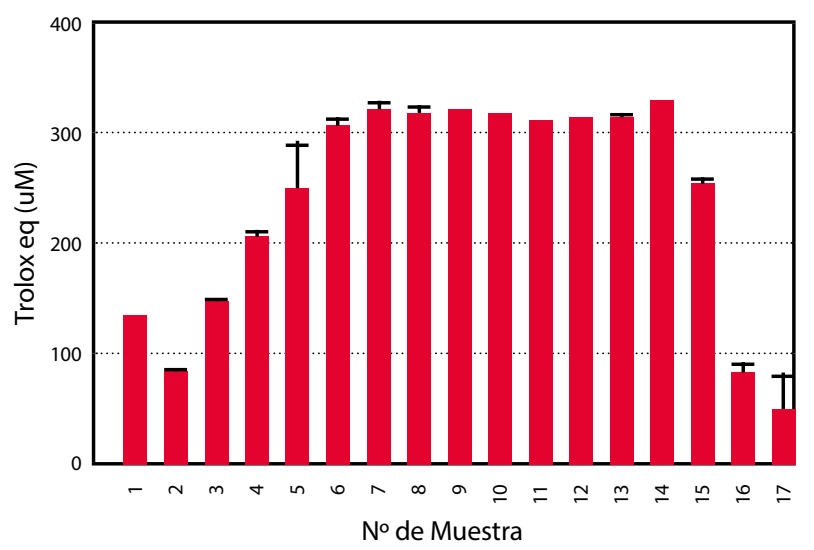

b.

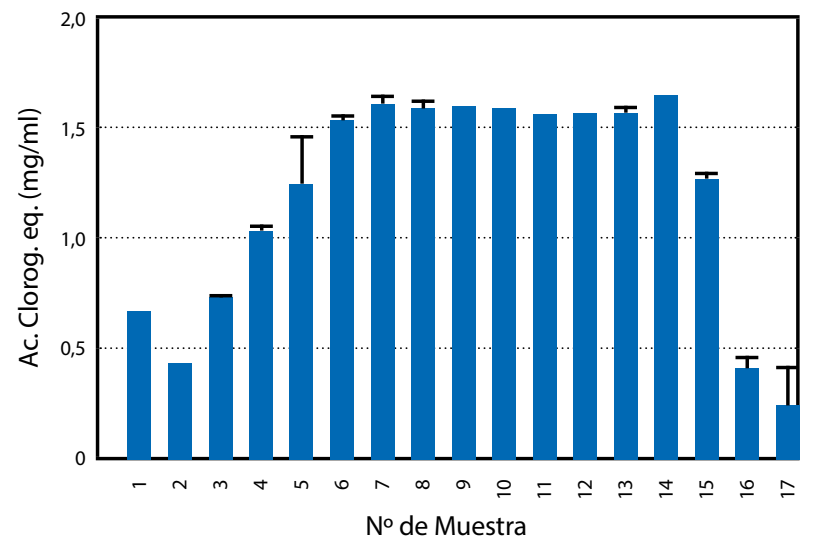

Figura 4. a. Valor Trolox eq $(\mu \mathrm{M})(\mathrm{ORAC})$ de las muestras provenientes de HD. b. Valor Ácido clorogénico eq. (mg/ $\mathrm{ml}$ ) (HORAC) de las muestras provenientes de HD. Los resultados se expresan como el promedio $\pm S D(n=3)$.

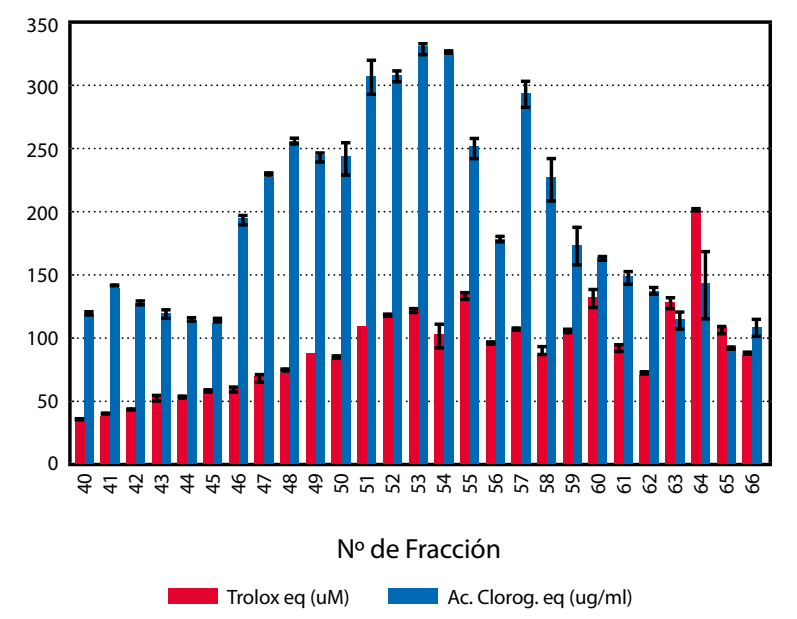

Figura 6. Valores Trolox eq $(\mu \mathrm{M})$ (ORAC) y Ácido Clorogénico eq. (ug/ml) (HORAC) para las fracciones constituyentes de las muestras 6-14 de HD. Los resultados se expresan como promedio $\pm S D(n=3)$.

tanto, para el ensayo HORAC las fracciones más activas fueron 51-54 y 57 con valores de ácido clorogénico eq. de entre 293 y $334 \mu \mathrm{g} / \mathrm{ml}$ y luego las fracciones $47-50,55$ y 58 , con valores de ácido clorogénico eq. de entre 209 y $303 \mu \mathrm{g} / \mathrm{ml}$ (Figura 6). 


\section{Simulación de la absorción intestinal}

Como método de evaluación de la formación e integridad de las monocapas celulares se realizaron medidas de TEER. Dicho parámetro aumentó durante la incubación hasta alcanzar un valor máximo aproximado de $350 \Omega . \mathrm{cm}^{2}$ luego de 12 días.

Dos fracciones con alta actividad antioxidante de cada una de las muestras fueron seleccionadas para evaluar su capacidad potencial de atravesar la pared intestinal: fracciones 50 y 52 de AD, y las 52 y 57 de HD (AD50, AD52, HD52 y HD57, respectivamente), con masas moleculares en el rango de $0,7-1,9 \mathrm{kDa}$, las cuales corresponderían a péptidos de entre 6 y 17 aminoácidos.

Previamente a los ensayos de evaluación de la absorción intestinal, se realizaron dos ensayos de citotoxicidad, MTT y Rojo Neutro, a fin de asegurar que las muestras no resultaran dañinas para las células en estudio. Los resultados mostraron que las cuatro muestras ensayadas no fueron citotóxicas en las concentraciones en las que se utilizaron, dado que las células mantuvieron en todos los casos una funcionalidad mitocondrial (MTT) y lisosomal (Rojo Neutro) completas.

Posteriormente se realizaron los ensayos de absorción incubando las monocapas confluentes de células Caco-2/ Tc7 crecidas sobre los insertos en presencia de las muestras colocadas en la cámara apical. Luego se tomó el contenido de las cámaras apical y basolateral para su análisis junto con la muestra original (fracción FPLC) correspondiente.

Como una primera medida de evaluación de la absorción de péptidos, se analizó la concentración de compuestos de naturaleza proteica. En la Tabla 1 se muestran los resultados expresados como la masa total de proteína en cada compartimiento.

\begin{tabular}{|c|c|c|c|}
\hline Muestra & Original & Apical & Basolateral \\
\hline AD50 & $64 \pm 1$ & $60 \pm 2$ & $48 \pm 5$ \\
AD52 & $11 \pm 2$ & $6 \pm 2$ & $10 \pm 3$ \\
HD52 & $17 \pm 2$ & $8 \pm 1$ & $19 \pm 1$ \\
HD57 & $56 \pm 1$ & $36 \pm 1$ & $34 \pm 2$ \\
\hline
\end{tabular}

Los resultados se expresan como el promedio \pm SD ( $n=2)$

Tabla 1. Cuantificación de proteínas ( $\mu \mathrm{g})$ en las muestras original, apical y basolateral de los ensayos de absorción.

En todos los casos la masa de péptidos detectada en la cámara apical luego de la incubación fue menor que la detectada en la muestra original (Tabla 1), sugiriendo que algunos de los péptidos presentes en cada muestra ingresaron a las células, pudiendo o no alcanzar la cámara basolateral. Todas las cámaras basolaterales presentaron un nivel detectable de péptidos (Tabla 1), lo cual indicaría que en todos los casos ocurrió absorción de péptidos. Sin embargo, cabe aclarar que los niveles de absorción (calculados como la proporción de péptidos en la cámara basolateral respecto a la muestra original) resultaron altos (superiores al $50 \%$ en todos los casos) respecto a lo esperado según los datos de la literatura (Renukuntla, et al., 2013). Además, la suma de las masas de péptidos de las dos cámaras superó en todos los casos la masa en la muestra original (incrementos de entre 23 y $70 \%$ ). Estos hechos sugieren que las cantidades de péptidos detectadas podrían contener un aporte de componentes ajenos a las muestras, probablemente procedentes de las células. En este sentido, se ha demostrado que monocapas de células Caco-2 crecidas sobre membranas semiporosas e incubadas (4-6 h) en presencia de metionina marcada radiactivamente liberan moléculas proteicas tales como apolipoproteínas, transferrina y factor de crecimiento entre otras, preferencialmente en la cámara basolateral, sin necesidad de señales específicas (Rindler y Traber, 1988). En base a esta información, se hipotetiza que en este estudio haya ocurrido secreción de alguna proteína celular a la cámara basolateral y por eso la suma de los valores de ambas cámaras fue superior a la cantidad detectada en la muestra original.

Se analizaron mediante RP-HPLC las muestras originales, junto con los contenidos de las cámaras apical y basolateral luego de la incubación, para evidenciar el pasaje de componentes peptídicos así como su posible modificación por acción del contacto con las células. Cabe considerar para este análisis que por necesidad del sistema de ensayo el volumen de la cámara basolateral fue tres veces mayor al de la cámara apical, por lo que los componentes detectados se encuentran más diluidos en la primera.
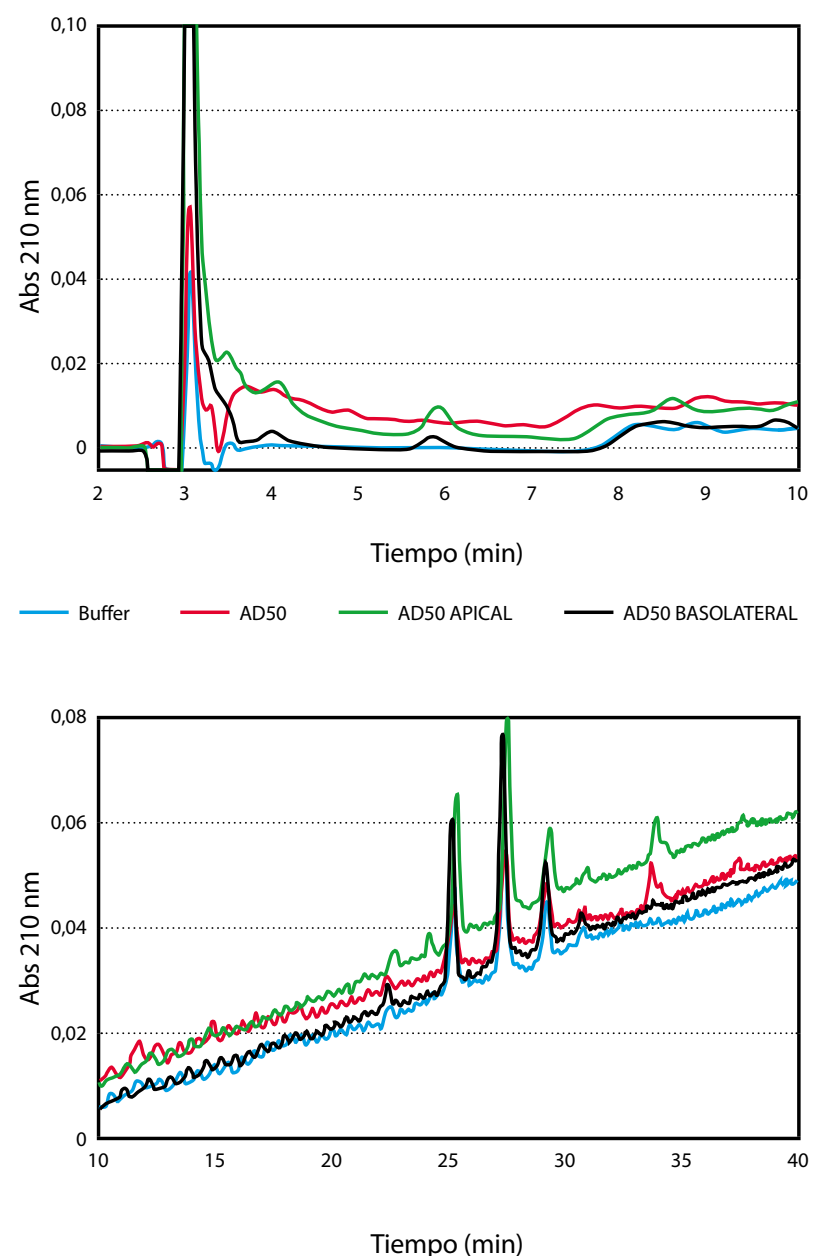

- Buffer $\longrightarrow$ AD50 AD50 APICAL - AD50 BASOLATERAL

Figura 7. Cromatogramas RP-HPLC de la fracción AD50 original y las cámaras apical y basolateral luego del ensayo de simulación de la absorción intestinal. 

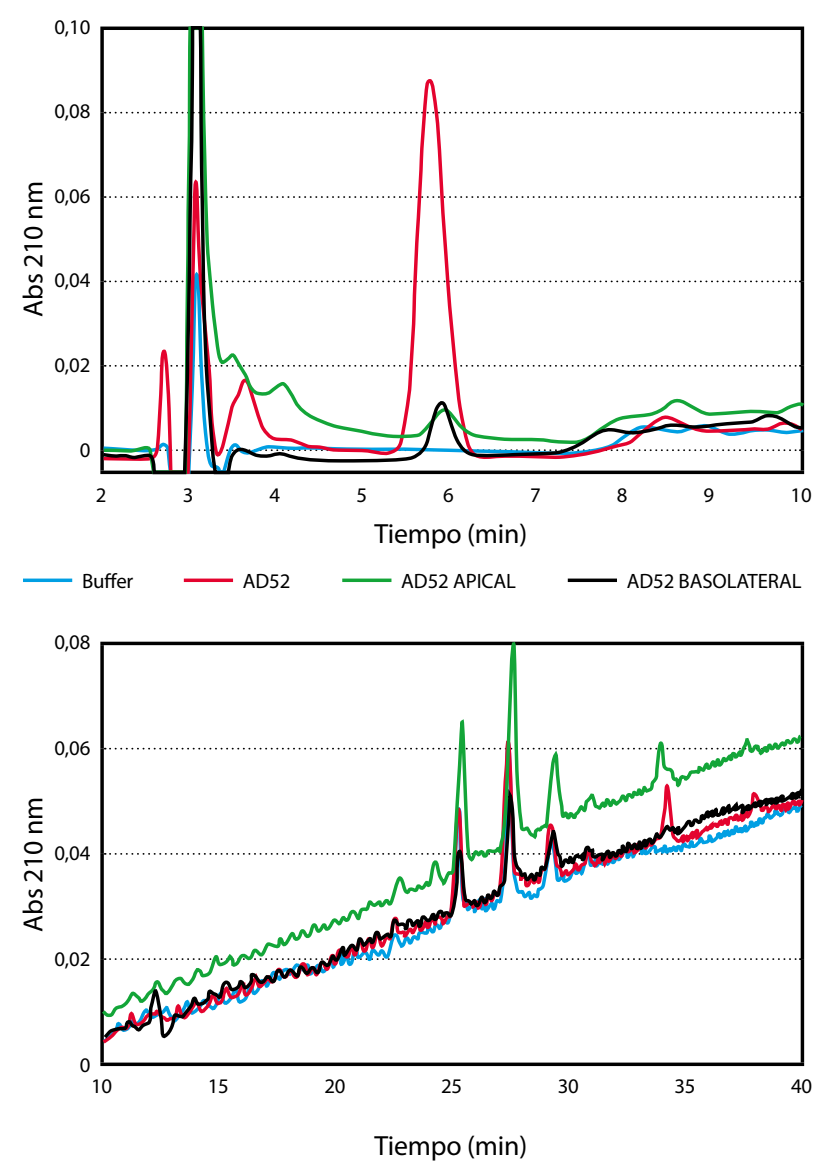

Buffer $\longrightarrow$ AD52 - AD52 APICAL

AD52 BASOLATERAL

Figura 8. Cromatogramas RP-HPLC de la fracción AD52 original y las cámaras apical y basolateral luego del ensayo de simulación de la absorción intestinal.

La fracción AD50 presentó una diversidad de picos. Descartando aquellos correspondientes al tampón, pueden mencionarse tres grupos de componentes: 1) Moléculas que aparecen entre los 3,5 y 7 min (hidrofílicas); 2) moléculas que aparecen entre los 12 y 15 min (picos muy pequeños); 3 ) moléculas que aparecen entre los 33 y 40 min (las más hidrofóbicas). El perfil RP-HPLC de la cámara apical presentó algunos cambios respecto al de $\mathrm{AD} 50$, tales como modificaciones en el primer grupo al inicio del cromatograma, disminución de los picos con $\mathrm{t}_{\mathrm{R}}$ entre 12 y $15 \mathrm{~min}$, y la aparición de dos picos pequeños ( $t_{R}=6$ y $24 \mathrm{~min}$ ) (Figura 7), sugiriendo que sus componentes podrían haber sido generados por acción de las peptidasas celulares sobre péptidos originalmente presentes en AD50. El perfil cromatográfico de la cámara basolateral muestra moléculas muy hidrofílicas ( $t_{R}$ entre 3 y 5 min) y un pico a $t_{R}=34$ min (Figura 7) presentes tanto en AD50 como en AD50 apical, lo cual indicaría que dichos componentes de este pico podrían haber sido parcialmente absorbidos sin modificaciones por parte de las células, aunque no se pueda asegurar que las moléculas constituyentes sean las mismas en las diferentes muestras. También apareció el pico de $t_{R}=6$ min generado en AD50 apical.

La fracción AD52 presentó picos correspondientes a moléculas hidrofílicas con $\mathrm{t}_{\mathrm{R}}$ menores a $4 \mathrm{~min}$, un pico muy
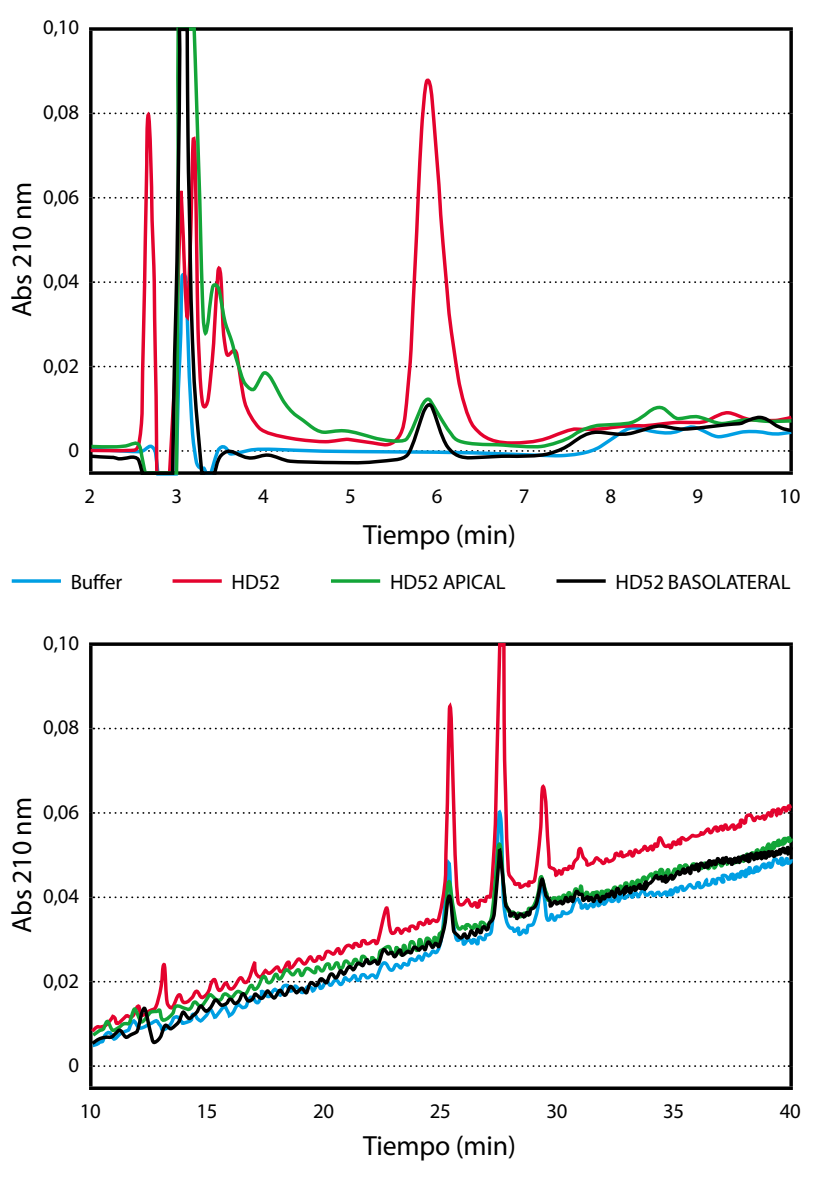

Buffer $\longrightarrow$ HD52 HD52 APICAL — HD52 BASOLATERAL

Figura 9. Cromatogramas RP-HPLC de la fracción HD52 original y las cámaras apical y basolateral luego del ensayo de simulación de la absorción intestinal.

importante a $t_{R}=6$ min y picos correspondientes a moléculas más hidrofóbicas similares a los detectados en AD50 (34 y $38 \mathrm{~min}$ ) (Figura 8). En la cámara apical se detectaron modificaciones en los picos al inicio del cromatograma $\left(t_{R}<4\right.$ $\min$ ), una disminución muy importante en el pico de $t_{R}=6$ min, una pequeña disminución de las especies más hidrofóbicas y la aparición de un pico con $t_{R}=24 \min$ (Figura 8). La cámara basolateral presentó el pico correspondiente $a t_{R}=6$ min y un pico con $t_{R}=13$ min, el cual no fue detectado en la cámara apical ni en la muestra original (Figura 8). Una posible explicación a la aparición de estas nuevas moléculas podría ser la modificación por peptidasas de moléculas originalmente presentes en el medio y su absorción en una alta proporción.

También fueron analizadas fracciones provenientes del digerido previamente hidrolizado con alcalasa. La fracción HD52 presentó algunas similitudes con la fracción AD52, tales como picos a tiempos menores a 4 min y un pico muy importante $a t_{R}=6 \mathrm{~min}$, aunque en este caso también se registraron picos a $t_{R}=13$ y $17 \mathrm{~min}$, sin presencia detectable de los picos correspondientes a moléculas más hidrofóbicas (Figura 9). Luego de la incubación con las células, la cámara apical presentó modificaciones en los picos al inicio del cromatograma, así como una disminución importante en la intensidad de los picos a $t_{R}=6$ y $13 \mathrm{~min}$, la desaparición 


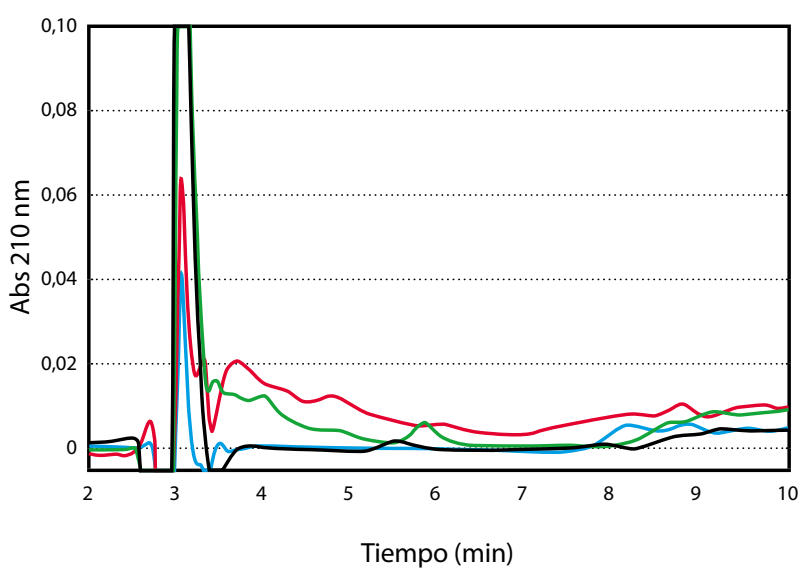

- Buffer $\longrightarrow$ HD57 - HD57 APICAL $\longrightarrow$ HD57 BASOLATERAL

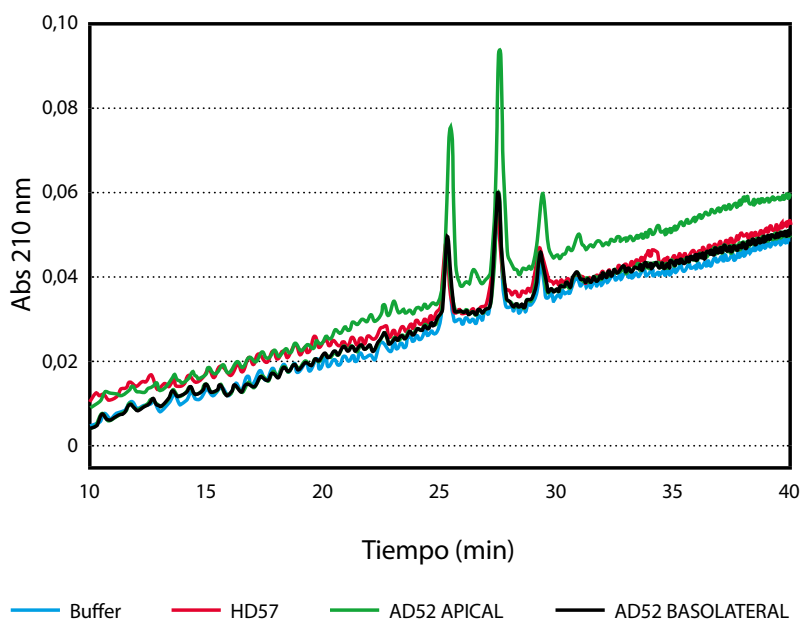

Figura 10. Cromatogramas RP-HPLC de la fracción HD57 original y las cámaras apical y basolateral luego del ensayo de simulación de la absorción intestinal.

del pico a $t_{R}=17$ min y la aparición de pequeños picos entre los 8 y 12 min (Figura 9). El perfil RP-HPLC de la cámara basolateral indica que se habrían absorbido componentes correspondientes a picos de $t_{R}=6,10$ y 13 min (Figura 9).

Finalmente, la fracción HD57 presentó moléculas hidrofílicas con $t_{R}$ menores a 5 min, unos picos muy pequeños con tiempos entre 8 y 13 min y un pico con $t_{R}=34$ min (Figura 10). La cámara apical correspondiente presentó una disminución de todos los picos observados en la muestra original y la aparición de picos a $t_{R}=6,23$ y 26 min (Figura 10), los cuales podrían ser atribuidos a la acción de peptidasas celulares sobre péptidos originales. La cámara basolateral presentó un único pico detectable con $t_{R}=6$ min (Figura 10).

Dadas las pequeñas cantidades de péptidos/proteínas con las que se está trabajando no se puede descartar en las muestras la presencia de moléculas que no pudieron ser detectadas en estos análisis de RP-HPLC. Si bien, como se describió en la sección anterior, la determinación de componentes peptídicos por el método de Lowry dio indicios de una posible secreción de proteínas celulares en la cámara basolateral, el análisis RPHPLC de las cámaras no permite confirmar este hecho. En el caso de ocurrir esta secreción, se esperaría la aparición en todas las cámaras basolaterales de picos idénticos, los cuales no estarían presentes en la cámara apical. Dado que esto no fue observado en los cromatogramas obtenidos, no se puede confirmar una secreción de proteínas celulares y tampoco es posible descartarla, ya que los productos de secreción podrían eluir junto con otros péptidos de amaranto o estar en concentraciones no detectables por este método.

\section{Evaluación de la actividad antioxidante}

Mediante el ensayo ORAC se analizó la actividad antioxidante de las cámaras apical y basolateral en comparación con sus correspondientes muestras originales. Los resultados se expresan como actividad específica ( $\mu \mathrm{g}$ de Trolox/ $\mu \mathrm{g}$ de péptidos) para poder realizar la comparación entre las distintas muestras (Tabla 2).

En primer lugar, es importante remarcar que la actividad específica de las distintas muestras originales fue diferente, dado que, si bien su actividad absoluta había presentado valores bastante cercanos (Figuras 5 y 6), la cantidad de componentes peptídicos detectados en cada caso es diferente (Tabla 1). Así, la actividad específica de las muestras AD52 y HD52 fue aproximadamente tres veces mayor que la de las muestras AD50 y HD57, indicando la presencia en las primeras de componentes más activos (Tabla 2). Como característica común de las dos primeras muestras puede resaltarse la presencia de un pico muy importante con $t_{R}=6$ min no presente en las otras dos muestras (Figuras 7, 8, 9 y 10).

\begin{tabular}{|l|c|c|}
\hline \multicolumn{1}{|c|}{ Muestra } & $\begin{array}{c}\mu g \text { Trolox/ug } \\
\text { proteína }\end{array}$ & $\begin{array}{c}\text { \% respecto } \\
\text { muestra original }\end{array}$ \\
\hline AD50 & $0,09 \pm 0,01^{\mathrm{a}}$ & \\
AD50 apical & $0,11 \pm 0,01^{\mathrm{a}}$ & 119 \\
AD50 basolateral & $0,13 \pm 0,01^{\mathrm{b}}$ & 143 \\
AD52 & $0,39 \pm 0,03^{\mathrm{a}}$ & \\
AD52 apical & $0,58 \pm 0,07^{\mathrm{b}}$ & 151 \\
AD52 basolateral & $0,48 \pm 0,02^{\mathrm{c}}$ & 126 \\
HD52 & $0,32 \pm 0,01^{\mathrm{a}}$ & \\
HD52 apical & $0,60 \pm 0,03^{\mathrm{b}}$ & 184 \\
HD52 basolateral & $0,15 \pm 0,01^{\mathrm{c}}$ & 47 \\
HD57 & $0,10 \pm 0,01^{\mathrm{a}}$ & \\
HD57 apical & $0,15 \pm 0,01^{\mathrm{b}}$ & 143 \\
HD57 basoalteral & $0,23 \pm 0,08^{\mathrm{c}}$ & 223 \\
\hline
\end{tabular}

Los resultados se expresan como el promedio \pm SD $(n=3)$.

Tabla 2. Valor ORAC de muestras provenientes de ensayos de absorción.

Luego de la incubación en presencia de las células Caco2/ TC7, la actividad de todas las muestras en la cámara apical se vio aumentada, excepto para la muestra $\mathrm{AD} 50$ en la que la diferencia no fue significativa $(\mathrm{p}<0,05)$ (Tabla 2). Sin embargo, pueden describirse distintos comportamientos para cada muestra respecto a la cámara basolateral. 
En el caso de AD50, la cámara basolateral presentó una mayor actividad específica en relación a la muestra original e incluso en relación a la cámara apical (Tabla 2), lo cual sugiere que las modificaciones (hidrólisis) producidas por las peptidasas celulares fueron beneficiosas, ya que generaron componentes más activos absorbiendo moléculas con alta actividad. En el caso de la muestra AD52, si bien había presentado un mayor aumento de actividad específica ORAC en la cámara apical, la cámara basolateral tuvo una actividad algo menor que esta (aunque mayor que la de la muestra original) (Tabla 2), indicando que si bien se generaron componentes más activos por acción de las células, estos no lograrían ser completamente absorbidos.

La muestra HD52 fue la menos favorable desde el punto de vista de la absorción de componentes antioxidantes, ya que si bien se produjo un importante incremento de actividad en la cámara apical, la actividad específica de la cámara basolateral fue del $47 \%$ respecto a la de la muestra original (Tabla 2). Finalmente, en el caso de la muestra HD57 el comportamiento fue similar al de la muestra AD50, ya que se observó un aumento de actividad específica de la cámara basolateral respecto a la apical, aunque en este caso mayor que en AD50 (Tabla 2). Como característica común de las fracciones AD50 y HD57 puede mencionarse la presencia en ambas de moléculas con altos $t_{R}$ (más hidrofóbicas), no detectadas en las otras muestras.

\section{Conclusiones}

La evaluación de la potencial absorción intestinal de cuatro fracciones con alta actividad antioxidante derivadas de $\mathrm{A}$ y $\mathrm{H}$ demostró que ciertos péptidos podrían ser absorbidos a través de la monocapa de células Caco-2-TC7, previa modificación o no por parte de las peptidasas celulares. Con base en los resultados encontrados mediante los análisis de RP-HPLC y aunque cada una de las muestras tuvo un comportamiento particular, se pueden derivar algunas características comunes a todas ellas: 1) Aunque con diferente perfil, todas las muestras presentaron un grupo de moléculas muy hidrofílicas (inicio de los cromatogramas), las cuales sufrieron modificaciones y/o absorción luego de la incubación con la monocapa de células Caco2/TC7;2) todas las cámaras apicales presentaron la aparición de algún/os pico/s no presente/s en las correspondientes muestras originales, posiblemente relacionados con la aparición de nuevos péptidos producto de la hidrólisis por parte de peptidasas celulares del borde en cepillo; 3 ) en todos los casos se observó absorción de componentes que aparecen a tiempos de elución menores a los $15 \mathrm{~min}$.

Respecto a la actividad antioxidante, en los cuatro casos se observó un comportamiento diferente. Si bien en todos los casos el potencial antioxidante (expresado como actividad específica) se vio aumentado en la cámara apical respecto a las muestras originales, sugiriendo un efecto beneficioso de la acción de las peptidasas, el comportamiento luego de la absorción fue variable y dependió del tipo de moléculas que logró atravesar la monocapa en cada caso. Sin embargo, como ya se ha mencionado, no es posible descartar completamente la presencia en las cámaras basolaterales de alguna/s proteína/s secretadas/s por las células; los diferentes comportamientos frente a la actividad antioxidante de cada muestra dan un indicio de su relación con las diferentes moléculas que pudieron ser absorbidas en cada caso. Un aumento en la actividad de la cámara apical respecto a la muestra original indica la generación potencial en la luz intestinal de moléculas más activas que podrían actuar a ese nivel por efecto directo sobre especies reactivas presentes en el contenido intestinal.

Estos estudios constituyen una primera aproximación al estudio de la absorción de péptidos con capacidad antioxidante derivados de proteínas de amaranto. Los resultados son prometedores ya que sugieren una absorción potencial de componentes antioxidantes, abriendo la posibilidad de que estos puedan ser capaces de actuar en el interior del organismo.

\section{Referencias}

Antunes, F, Andrade, F, Araújo, F, Ferreira, D, y Sarmento, B., 2013. Establishment of a triple co-culture in vitro cell models to study intestinal absorption of peptide drugs. En: European Journal of Pharmaceutics and Biopharmaceutics, (83), pp.427-435.

Di Virgilio, A., Reigosa, M., Arnal, P. y Fernandez Lorenzo de Mele, M., 2010. Comparative study of the cytotoxic and genotoxic effects of titanium oxide and aluminium oxide nanoparticles in Chinese hamster ovary (CHO-K1) cells. En: Journal of Hazardous Materials, (177), pp.711-718.

Hidalgo, I., Ruba, T. y Borchardt, R., 1989. Characterization of the human colon carcinoma cell line (Caco-2) as a model system for inestinal epithelial permeability. En: Gastroenterology, (96), pp.736-749.

Martínez, E. y Añón, M., 1996. Composition and structural characterization of amaranth protein isolates. An electrophoretic and calorimetric study. En: Journal of Agricultural and Food Chemistry, (44), pp.2523-2530.

Orsini Delgado, M., Tironi, V. y Añón, M., 2011. Antioxidant activity of amaranth proteins or their hydrolysates under simulated gastrointestinal digestion. En: LWT-Food Science and Technology, (44), pp.1752-1760.

Orsini Delgado, M., Galleano, M., Añón, M. y Tironi, V., 2015. Amaranth peptides from gastrointestinal digestion: antioxidant activity against physiological reactive species. En: Plant Foods for Human Nutrition, (70), pp.27-34.

Quiros, A, Davalos, A, Lasuncion, M, y Ramos, M., 2008. Bioavailability of the antihypertensive peptide LHLPLP: Transepithelial flux of HLPLP. En: International Dairy Journal,(18), pp.279-286.

Regazzo, D, Molle, D, Gabai, G, Tome, G, Dupont, D, Leonil, J, y Boutrou, R., 2010. The (193-209) 17 residues peptide of bovine $\beta$-casein is transported through Caco-2 monolayer. En: Molecular Nutrition and Food Research, (54), pp.1-8.

Renukuntla, J. Dutt Vadlapudib, A, Patel, A, Boddu, S, Mitra, A., 2013. Approaches for enhancing oral bioavailability of peptides and proteins. En: International Journal of Pharmaceutics, (447), pp.75-93.

Rindler, M. y Traber, M., 1988. A specific sorting signal is not required for the polarized secretion of newly synthesized proteins from cultured intestinal epithelial cells. En: The Journal of Cell Biology, (107), pp.471-479.

Stoscheck, C., 1990. Quantitation of protein. En: Methods in Enzymology, (182), pp.50-69.

Tironi, V. y Añón, M., 2010. Amaranth as a source of antioxidant peptides. Effect of proteolysis. En: Food Research International, (43), pp.315 - 322.

Vermeirssen, V., Camp, J. y Verstraete, W., 2004. Bioavailability of angiotensin I converting enzyme inhibitory peptides. En: British Journal of Nutrition, 92(3), pp.357-366. 